\title{
Effect of behavioral intervention using smartphone application for preoperative anxiety in pediatric patients
}

\author{
Jong-Hyuk Lee ${ }^{2}$, Han-Kil Jung ${ }^{1}$, Gang-geun Lee ${ }^{1}$, Han-Young Kim ${ }^{1}$, Sun-Gyoo Park ${ }^{1}$, and \\ Seong-Chang Woo ${ }^{1}$
}

Department of Anesthesiology and Pain Medicine, ${ }^{1}$ Eulji University School of Medicine, Daejeon, ${ }^{2}$ Asan Medical Center, University of Ulsan College of Medicine, Seoul, Korea

Background: Children and parents experience significant anxiety and distress during the preoperative period. This is important because preoperative anxiety in children is associated with adverse postoperative outcome. So we suggest behaviorally oriented preoperative anxiety intervention program based on the anesthesia and psychology with smartphone application, world-widely used.

Methods: A total 120 patients (aged 1-10 years old) who were scheduled for elective surgery under general anesthesia was included in this randomized controlled trial. We randomized the patients into three groups, with using intravenous (IV) midazolam sedation (M group), with using smartphone application program (S group), and with using low dose IV midazolam plus smartphone application program (SM group). And the child anxiety was assessed using the modified Yale Preoperative Anxiety Scale (mYPAS) at holding area, 5 min after intervention, entrance to operating room.

Results: In all three groups, mYPAS after intervention were lower than the preoperative holding area (M group $52.8 \pm$ 11.8 vs $41.0 \pm 7.0$, S group $59.2 \pm 17.6$ vs $36.4 \pm 7.3$, SM group $58.3 \pm 17.5$ vs $26.0 \pm 3.4$ ). A comparison of mYPAS scores between each group showed that the $S$ group reduced anxiety lower than $M$ group $(\mathrm{P}<0.01)$, and the SM group exhibited significantly lower anxiety than the two other groups $(\mathrm{P}<0.01)$.

Conclusions: The preoperative preparation program using smartphone application is simple and customized by individual development that effective in the reduction of preoperative anxiety. (Korean J Anesthesiol 2013; 65: 508-518)

Key Words: Anxiety, Child, Preoperative care.

Received: April 3, 2013. Revised: May 20, 2013. Accepted: June 19, 2013.

Corresponding author: Seong-Chang Woo, M.D., Ph.D., Department of Anesthesiology and Pain Medicine, Eulji University School of Medicine, 1306, Dun-san 2-dong, Seo-gu, Daejeon 302-799, Korea. Tel: 82-42-611-3655, Fax : 82-42-482-9036, E-mail: woonoh@eulji.ac.kr

(c) This is an open-access article distributed under the terms of the Creative Commons Attribution Non-Commercial License (http:// creativecommons.org/licenses/by-nc/3.0/), which permits unrestricted non-commercial use, distribution, and reproduction in any medium, provided the original work is properly cited. 


\section{Introduction}

Anxiety is a negative emotional state arising from stressful or threatening circumstances [1]. Children about to undergo a medical operation and the children and their parents often experience anxiety during the preoperative period. Children are more vulnerable to anxiety than adults are owing to their levels of emotional and behavioral development. Therefore, they may be uncooperative and appear unable to handle the medical intervention. Then the anxiety cause physiological changes and lead to behavioral changes [2]. Kain et al. [3] reported that preoperative period anxiety is associated with an increased incidence of postoperative negative behaviors, an increased incidence of emergence delirium, and increased postoperative pain. Various intervention methods have been studied to treat preoperative anxiety and prevent the above issues. Currently available interventions for the treatment of preoperative anxiety include administration of sedatives before anesthesia (i.e., premedication), allowing parents to be present during induction of anesthesia, and providing a hospital-based preparation program before surgery. However, there are reports that many children still experience preoperative anxiety, as all of the above interventions have adverse effects or limitations [4-9].

Recently, studies have begun to investigate the potential of preoperative behavioral intervention programs to overcome such limitations. Kain et al. [3] developed a family-centered behavioral intervention program and demonstrated that it had a significant effect. Furthermore, there have emerged efficient behavioral intervention programs that use cartoons and video clips [10-12]. The authors of the present study hypothesized that using a smartphone application as part of a behavioral intervention program for Korean families, while taking into account individual characteristics, may be a simple and effective way to reduce preoperative anxiety in children. Hence, this study compared a behavioral intervention program using a smartphone application and induction of anesthesia through premedication to determine whether the former offered benefits in terms of reducing preoperative anxiety.

\section{Materials and Methods}

The study population consisted of 120 children aged 1-10 years who were within the American Society of Anesthesiologists physical status I or II and who were undergoing general anesthesia and elective surgery. Patients with a history of admission or surgery and those with cardiovascular disease, metabolic disease, or congenital disease were excluded from the study. The doses of the premedication and delivery of the behavioral intervention program were applied by following Cote [13] and Kain et al. [3].
In this study, children were randomly assigned into 3 groups: one that received an intravenous injection of $0.15 \mathrm{mg} / \mathrm{kg}$ midazolam through a secured intravenous line prior to the induction of anesthesia in the operating room (group $M, n=40$ ); one that participated in a behavioral intervention program through a smartphone application prior to the induction of anesthesia in the operating room (group $S, n=40$ ); and one that received an intravenous injection of $0.05 \mathrm{mg} / \mathrm{kg}$ midazolam as a small dose of sedatives through a secured intravenous line and underwent the behavioral intervention program through a smartphone application prior to the induction of anesthesia in the operating room (group SM, $\mathrm{n}=40$ ).

Child anxiety was assessed using the modified Yale Preoperative Anxiety Scale (mYPAS) (Appendix 1). Two doctors, the anesthesiologist and a doctor responsible for the rating and naive to the anesthesia, were assigned to each child patient. The rating doctor had thorough understanding of and training in assessing child's anxiety and was blinded for the study. In this study, children's parents were given a thorough explanation, and written informed consent was obtained.

The day before the scheduled elective surgery, all children and parents went through the admission process and received an explanation of this study. During the preoperative visit for preanesthesia evaluation, the children's developmental status and preferences regarding the behavioral intervention program were assessed through a preoperative visit survey (Appendix 2). During the explanation, parents were directed not to take any action to reduce their children's anxiety during the transfer from the admission room to the preoperative holding area. On the day of surgery, the rating doctor confirmed with parents whether they had taken any action to reduce their children's anxiety during this transfer, and then the rating doctor recorded the initial mYPAS score.

After the first mYPAS scoring, the children in group M were administered $0.15 \mathrm{mg} / \mathrm{kg}$ midazolam via intravenous injection as premedication through a secured intravenous line. Then, the children in group $S$ were given time to play with their preferred smartphone application as indicated on the preoperative visit survey; midazolam intravenous injection was not administered in this group. Five minutes later, the children in group SM were administered $0.05 \mathrm{mg} / \mathrm{kg}$ midazolam via intravenous injection as premedication through a secured intravenous line, and they were also given time to play with their preferred smartphone application. Five minutes later, the mYPAS score was recorded by the naive rating doctor.

After the first mYPAS scoring, the children were brought to the operating room 5 minutes after premedication or 5 minutes after the initiation of the application program, with continued use of the application. The induction of anesthesia was done while the children were on the cart, prior to being transferred to 
the operating bed, and the naive rating doctor recorded the last time mYPAS.

While on the patient cart, the child was connected to a pulse oximeter and electrocardiography lead, and $5 \mathrm{mg} / \mathrm{kg}$ thiopental sodium was intravenously administered for the induction of anesthesia while oxygenation was carried out through an anesthesia mask. After confirming the disappearance of eyelid reflex, the child was transferred to the operating bed, and the induction of anesthesia was initiated by increasing the sevoflurane concentration through the anesthesia mask. Regardless of the intervention grouping, children manifesting a mYPAS score of $\geq 70$ or an anxiety level not allowing them to enter the operating room were additionally administered $0.05 \mathrm{mg} / \mathrm{kg}$ of midazolam via intravenous injection prior to entering the operating room.

All data in this study are presented as the mean \pm standard deviation. SPSS 12.0 for Windows (SPSS Inc., Chicago, IL, USA) was used for statistical analysis, and the Kruskal-Wallis test, repeated-measures analysis of variance, and $\mathrm{x}^{2}$-test were used to test hypothesized within-group or between-group differences. As a post-hoc test, the Scheffé test was used to evaluate correlations associated with intervention methods at different points in time and in terms of individual effects. A P value of $<0.05$ was considered statistically significant.

Table 1. Demographic Data

\begin{tabular}{lccc}
\hline & $\begin{array}{c}\text { M group } \\
(\mathrm{n}=40)\end{array}$ & $\begin{array}{c}\text { S group } \\
(\mathrm{n}=40)\end{array}$ & $\begin{array}{c}\text { SM group } \\
(\mathrm{n}=40)\end{array}$ \\
\hline Age $(\mathrm{yr})$ & $5.7 \pm 2.2$ & $4.5 \pm 1.8$ & $5.0 \pm 2.4$ \\
Weight $(\mathrm{kg})$ & $21.1 \pm 4.3$ & $20.0 \pm 4.9$ & $20.1 \pm 5.5$ \\
Sex $(\mathrm{M} / \mathrm{F})$ & $22 / 18$ & $26 / 14$ & $26 / 14$ \\
\hline
\end{tabular}

Values are mean \pm SD or number. M group: midazolam $0.15 \mathrm{mg} / \mathrm{kg}$ IV premedication. S group: intervention with smart phone application. SM group: midazolam $0.05 \mathrm{mg} / \mathrm{kg}$ IV premedication and intervention with smart phone application.

\section{Results}

This study randomly assigned 120 subjects (1-10 years old) to 3 groups, and each group consisted of 40 patients. There was no statistically significant difference in age, gender, or weight between the groups (Table 1).

Regarding anxiety changes in the groups (Table 2), the mYPAS scores decreased significantly in 5 minutes after premedication and after entry into the operating room compared with the score in preoperative holding area across all 3 groups $(\mathrm{P}<0.01)$. The mYPAS score after entry into the operating room increased compared with the score 5 minutes after premedication, but the difference was not statistically significant $(\mathrm{P}>0.05)$.

Regarding differences between groups at different points in time (Table 2), group $M$ had lower mean mYPAS values in the preoperative holding area $(6.38 \pm 5.79,5.46 \pm 5.74)$ compared to groups $\mathrm{S}$ and $\mathrm{SM}$, but the differences were not statistically significant $(P=0.063)$. The mean values of mYPAS scores recorded 5 minutes after the intervention showed statistically significant differences between the 3 groups $(\mathrm{P}<0.01)$; the post-hoc test revealed that group $S$ was significantly lower than group $M(P$ $=0.004)$, group SM was significantly lower than group $\mathrm{M}(\mathrm{P}<$ $0.01)$, and group $\mathrm{SM}$ was significantly lower than group $\mathrm{S}(\mathrm{P}<$ 0.01 ). In addition, the mean values of mYPAS scores recorded after entry into the operating room showed statistically significant differences between the 3 groups $(\mathrm{P}<0.01)$; the post-hoc test showed that group $S$ was significantly lower than group $M(P$ $<0.01)$, group SM was significantly lower than $\mathrm{M}(\mathrm{P}<0.01)$, and group $\mathrm{SM}$ was significantly lower than group $\mathrm{S}(\mathrm{P}<0.01)$.

Children with an mYPAS score of $\leq 30$ recorded after entry into the operating room were classified as no anxiety (Table 2); 2 (5\%), 6 (15\%), 25 (62.5\%) children in groups M, S, and SM presented with no anxiety. There were a significantly greater number of no-anxiety subjects in group $\mathrm{S}$ compared with group $\mathrm{M}$ and in group SM compared with group $\mathrm{S}(\mathrm{P}<0.01)$.

Table 2. Preoperative Change of mYPAS in Different Group

\begin{tabular}{|c|c|c|c|c|}
\hline \multirow{2}{*}{ Children's Anxiety (mYPAS) } & \multicolumn{3}{|c|}{ Study group } & \multirow{2}{*}{$\mathrm{P}$ value } \\
\hline & $M$ group $(n=40)$ & $S$ group $(n=40)$ & SM group $(n=40)$ & \\
\hline Holding area & $52.8 \pm 11.8$ & $59.2 \pm 17.6$ & $58.3 \pm 17.5$ & 0.063 \\
\hline 5 min after intervention & $41.0 \pm 7.0 *$ & $36.4 \pm 7.3^{*}$ & $26.0 \pm 3.4^{*}$ & $\mathrm{P}<0.01$ \\
\hline In operation room & $44.8 \pm 6.5^{*}$ & $38.6 \pm 6.4^{*}$ & $30.2 \pm 3.5^{*}$ & $\mathrm{P}<0.01$ \\
\hline No anxiety (n) & 2 & 6 & 25 & $\mathrm{P}<0.01$ \\
\hline MDZ add. (n) & 1 & 2 & 0 & \\
\hline
\end{tabular}

Values are mean \pm SD or number. M group: midazolam $0.15 \mathrm{mg} / \mathrm{kg}$ IV premedication. S group: intervention with smart phone application. SM group: midazolam $0.05 \mathrm{mg} / \mathrm{kg}$ IV premedication and intervention with smart phone application. No anxiety: the number of children whose scores indicated no anxiety (mYPAS score $<30$ ) at operation room. MDZ add.: the number of children who needs additional midazolam premedication $0.05 \mathrm{mg} / \mathrm{kg}$ IV for high mYPAS score (mYPAS $>70)$. $* \mathrm{P}<0.05$ compared with holding area. In all three group, the preoperative anxiety scale after intervention and in operation room were lower than the holding area $(\mathrm{P}<0.01)$. A comparison of mYPAS scores between each group showed that the $\mathrm{S}$ group reduced anxiety lower than M group $(\mathrm{P}<0.01)$, and the SM group exhibited significantly lower anxiety than the two other groups $(\mathrm{P}<0.01)$. The number of no anxiety in each group showed that the SM group had the significantly highest number than the two other groups $(\mathrm{P}<0.01)$. 
The number of children that had difficulty entering the operating room due to a mYPAS score of 70 or higher despite the premedication or intervention-and thus required an additional intravenous injection of midazolam $0.05 \mathrm{mg} / \mathrm{kg}$-was 1 in group $\mathrm{M}$ and 2 in group S (Table 2).

The results of the preoperative visit survey were classified according to age based on developmental stage, and the preferred smartphone applications selected by children in each group were listed. Regarding the characteristics of developmental stages, the use of language and social and adaptive play were notably different at around 3 years of age, while listening to and understand- ing stories was notably different at around 18 months of age. The children were further subdivided based on additional characteristics of each developmental stage. The following smartphone applications were the most preferred in each age group: (SoundTouch interactive ${ }^{\circledR}$, SoundTouch Interactive LTD., Ein Habesor, Israel) at 12-18 months of age; (Hutos ${ }^{\circledR}$ vod, Cotton Interective LTD., Seoul, Korea) and (Pororo Sticker Book ${ }^{\circledR}$, OCON Inc., Seoul, Korea) at 18-36 months of age; (Pororo Sticker Book ${ }^{\circledR}$, OCON Inc., Seoul, Korea) (30.77\%) and (Talking Tom Cat ${ }^{\circledR}$, Out Fit 7 Ltd, Ljublijana, Slovenia) (30.77\%) at 36-48 months of age; and (Angry Birds ${ }^{\circledR}$, Rovio Mobile Ltd., Keilaranta, Finland)

Table 3. Developmental Stage Characteristics by Age and Application Preference

\begin{tabular}{|c|c|c|c|}
\hline Age & $\mathrm{n}$ & Developmental stage characteristics & Application preference \\
\hline \multirow[t]{5}{*}{$12-18$ month } & 7 & Say "mama", "dada" & Soundtouch interactive ${ }^{\circledR}(71.42 \%)$ \\
\hline & & Vocalizes “no”, 10 words & Pororo sticker book $^{\circledR}(28.57 \%)$ \\
\hline & & Strong dependence on primary caregiver (Difficult to separate) & \\
\hline & & Feeds self with fingers & \\
\hline & & Points and vocalizes to indicate wants & \\
\hline \multirow[t]{4}{*}{$18-24$ month } & 4 & Use spoon with little spilling & Hutos $^{\circledR} \operatorname{vod}(41.67 \%)$ \\
\hline & & Enjoys simple stories & Pororo sticker book ${ }^{\circledR}(41.67 \%)$ \\
\hline & & Speak in 2 word sentences & Eznetsoft software $^{\circledR}$ \\
\hline & & Understanding "yours" \&"mine" & "The little Mermaid", "Hansel and Gretel" (16.67\%) \\
\hline \multirow[t]{3}{*}{ 24-36 month } & 8 & Use phrases and 4 word sentences & \\
\hline & & Initiates own play activities & \\
\hline & & Joins in rhymes and songs & \\
\hline \multirow[t]{5}{*}{$36-48$ month } & 13 & Uses language to resist & Pororo sticker book ${ }^{\circledR}(30.77 \%)$ \\
\hline & & Converses in sentences & Talking tom $\mathrm{cat}^{\circledR}(30.77 \%)$ \\
\hline & & Answers simple yes/no questions & Angry bird $^{\circledR}(23.08 \%)$ \\
\hline & & & Eznetsoft software $^{\circledR}$ \\
\hline & & & "The little Mermaid", "Hansel and Gretel" (23.08\%) \\
\hline \multirow[t]{3}{*}{ Over 4 year } & 48 & Express language & Angry birds $^{\circledR}(85.42 \%)$ \\
\hline & & Shows curiosity & Eznetsoft software $^{\circledR}$ \\
\hline & & Ask many questions & "The little mermaid", "Hansel and gretel" (14.58\%) \\
\hline
\end{tabular}

A

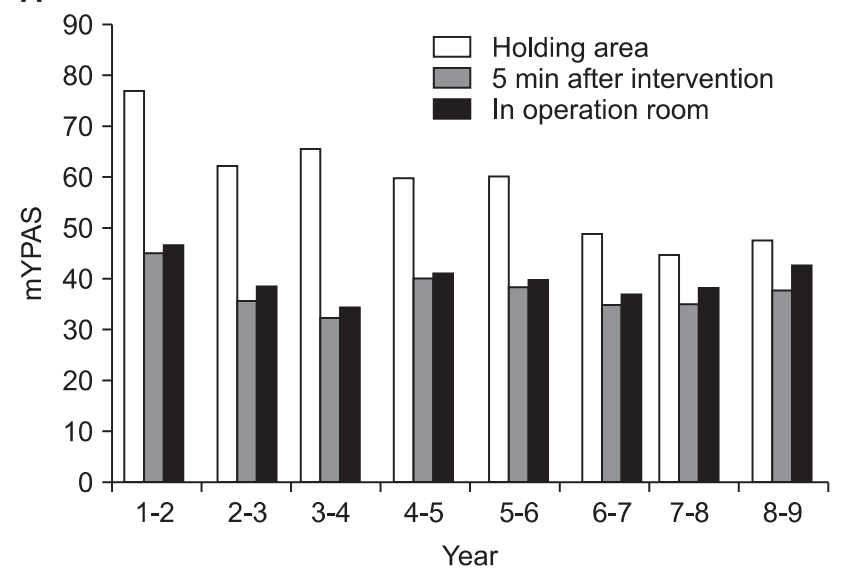

B

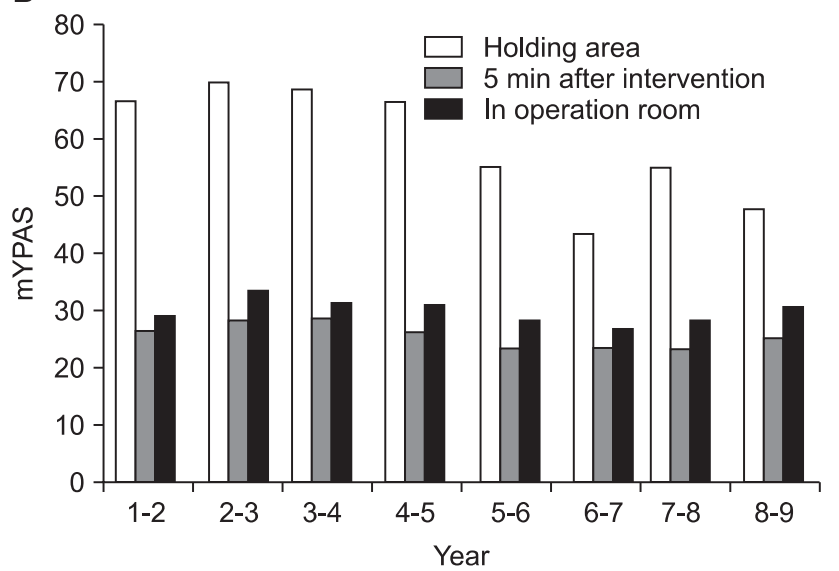

Fig. 1. (A) The change of preoperative anxiety by age in S group. (B) The change of preoperative anxiety by age in SM group. Values are mean of the modified Yale Preoperative Anxiety Scale (mYPAS). S group: intervention with smart phone application. SM group: midazolam $0.05 \mathrm{mg} / \mathrm{kg}$ IV premedication and intervention with smart phone application. mYPAS at $5 \mathrm{~min}$ after intervention, in operation room was lowered than mYPAS at holding area, but there is no specific tendency of mYPAS change by age. mYPAS at holding area tend to decrease as the age increased. Preoperative change of anxiety was influenced by age at holding area. 
(85.42\%) in children 48 months of age or older (Table 3). (Eznetsoft Software ${ }^{\circledR}$, Eznetsoft INC., Anyang, Korea) less preferred in children 18 months of age or older.

Differences in mYPAS scores according to the intervention methods (group S vs. SM) based on age and at different points in time are presented in Fig. 1. In these 2 groups, no particular agerelated trend was observed in the mean of the mYPAS scores recorded 5 minutes after the intervention and inside the operating room; the values were low, at around 40 and 30 in group S and group SM, respectively. However, the mean mYPAS value of group $S$ in the preoperative holding area was highest among those aged 1-2 years and decreased as ages increased; values were 77.22 among those aged 1-2 years, 62.33 among those aged 2-3 years, 65.74 among those aged 3-4 years, and 60 or higher among those aged $1-4$ years (Fig. 1A). The mean mYPAS value of group SM in the preoperative holding area was highest among those aged 2-3 years and decreased with ages increased; values

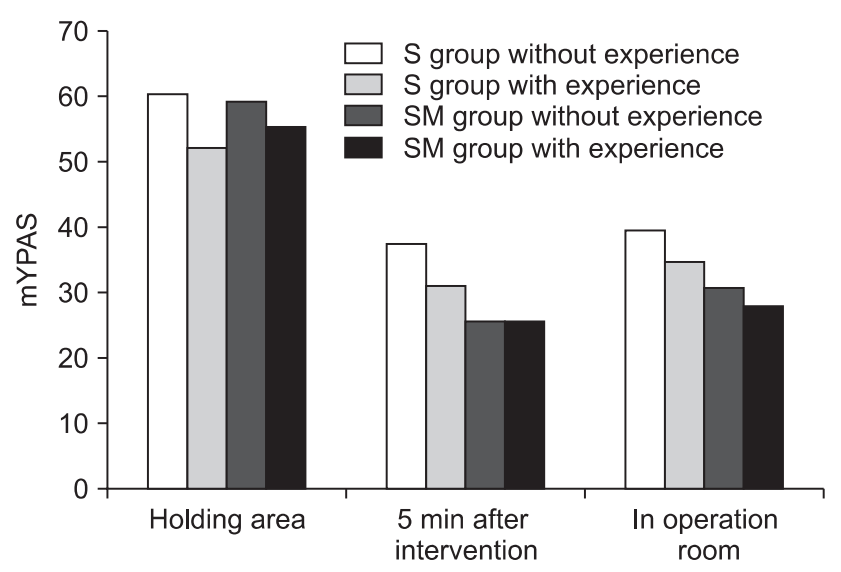

Fig. 2. mYPAS of the group with experience was lower than mYPAS of the group without experience in S, SM group. Preoperative change of anxiety was influenced by familiarity with smartphone application. $S$ group: Intervention with smartphone application. SM group: Midazolam premedication $0.05 \mathrm{mg} / \mathrm{kg}$ IV + Intervention with smartphone application. The group without experience: child who have not enjoyed playing smartphone application yet. The group with experience: child who have enjoyed playing smartphone application for more than a day. Values are mean mYPAS. were 66.67 among those aged 1-2 years, 69.76 among those aged 2-3 years, 68.75 among those aged 3-4 years, 66.39 among those aged $4-5$ years, and 60 or higher among those aged $1-5$ years (Fig. 1B).

Fig. 2 shows tendencies in mYPAS differences according to intervention time and method (group S, group SM) based on whether children had experience using smartphone applications. Children that had used smartphone applications for at least 1 day were classified as the group with such experience, and children with no experience using smartphone applications were classified as the group without such experience. The mean mYPAS values of group S 5 minutes after the intervention were 31.19 in the group with experience and 34.76 in the group without experience; after entry into the operating room, the values were 34.76 in the group with experience and 39.49 in the group without experience. The mean mYPAS values of group SM 5 minutes after the intervention were 25.93 in the group with experience and 25.97 in the group without experience; after entry into the operating room, the values were 28.15 in the group with experience and 30.81 in the group without experience. Among these scores, those recorded as $\leq 30$ after entry into the operating room were classified additionally as no anxiety, and the rates are presented in Table 4.

In group $\mathrm{S}$, the difference between the ratio of no-anxiety children in the groups with and without smartphone application experience was significant: 43 and $9 \%$, respectively $(\mathrm{P}<0.05)$. In group $\mathrm{SM}$, the difference between the ratio of no-anxiety children in the groups with and without smartphone application experience was not significant: 78 and 55\%, respectively (P = $0.216)$.

\section{Discussion}

This study applied smartphone applications that are easily accessible in Korea to a behavioral intervention program for fast and effective reduction of preoperative anxiety in children, and its effect was confirmed via statistical methods. In this study, group $\mathrm{S}$, in which children used a smartphone application, presented significantly lower mYPAS values compared with group

Table 4. The Effect of Familiarity with Smartphone Application on The Rate of Anxiety Relief

\begin{tabular}{|c|c|c|c|c|c|c|}
\hline & \multicolumn{3}{|c|}{$S$} & \multicolumn{3}{|c|}{ SM } \\
\hline & $\mathrm{n}$ & No anxiety (n) & No anxiety (\%) & $\mathrm{n}$ & No anxiety (n) & No anxiety (\%) \\
\hline Without experience & 33 & 3 & 9 & 31 & 17 & 55 \\
\hline With experience & 7 & 3 & 43 & 9 & 7 & 78 \\
\hline$P$ value & & & 0.023 & & & 0.216 \\
\hline
\end{tabular}

S group: intervention with smart phone application. SM group: midazolam $0.05 \mathrm{mg} / \mathrm{kg}$ IV premedication and intervention with smart phone application. Without experience: child who have not enjoyed playing smartphone application yet. With experience: child who have enjoyed playing smartphone application for more than a day. No anxiety: the number of children whose scores indicated no anxiety $(\mathrm{mYPAS}$ score $<30)$ at operation room. 
$\mathrm{M}$, in which children were only administered premedication. In addition, in group SM, which combined use of a smartphone application with a low dose of midazolam as premedication, children's mYPAS values were significantly reduced compared with the previous 2 groups.

Children are still progressing in their psychosocial development; hence, they are susceptible to preoperative period anxiety. Anxiety in young children is easily stimulated; they easily become frightened and agitated due to various causes, such as the unfamiliar hospital environment, strangers (including medical professionals), lack of understanding about their health status and treatments, fear of physical injury, and separation from their parents. Anxiety manifests in age-specific ways based on developmental stage; very young children (1-3 years old) may experience separation anxiety from their parents and familiar home. Somewhat older children (4-6 years old) fear surgery. Older children and adolescents may fear awakening during surgery and the possibility of not recovering from anesthesia. Adolescents may fear the loss of self-control, the loss of autonomy, and the loss of consciousness. They also fear pain and the possibility of death. Some children verbally express their fears, while others express them through negative behaviors or physiological changes. As a result, preoperative anxiety has been reported to cause negative behaviors such as night terrors, separation anxiety, eating disorders, and excessive tremors; it also increases the incidence of emergence delirium, increases the consumption of analgesics by exacerbating postoperative pain, and increases the duration of postoperative hospital stays [3]. Therefore, understanding the effect of children's age and developmental stage on anxiety can lead to an appropriate intervention program for changing postoperative behavior and promoting physiological benefits [14].

Until recently in Korea, premedication interventions were frequently used for the treatment of anxiety in pediatric anesthesia. It has been reported that sedative premedication was superior to parental presence during induction of anesthesia or no intervention in controlling anxiety [9]. On the other hand, in cases of short surgery or outpatient surgery, there are disadvantages, such as increases in hospital cost, delays in entry into the operating room, and prolonged stays in the recovery room [2]. Premedication also has limitations related to adverse drug effects with overdose, such as respiratory depression, and overexcitation after surgery $[9,15]$. Various studies have investigated other methods to reduce anxiety due to such disadvantages. A variety of methods have been attempted, including administration routes other than oral and intravenous, such as intranasal, subcutaneous, intramuscular injection [16-18]. Other attempted methods include parental presence during induction of anesthesia [9], use of music [6], use of toys [8] and education with pamphlets or videos [3]. For all of these methods, however, lim- ited benefits and effectiveness have been revealed. Kain et al. [3] combined methods in developing a structured family-centered behavioral intervention program. These authors published a study that proved the significance of its effect through a randomized controlled trial. Kain et al. [3] reported that it relieved anxiety in children and their parents, as well as led to better results than sedative premedication in the incidence of postoperative delirium, consumption of analgesics, and duration of postoperative hospital stay. In addition, simple and effective behavioral intervention programs using portable video games, cartoons, and video clips have recently been introduced [10-13].

This study applied smartphone applications that are widespread across the world and easily accessible in Korea to a behavioral intervention program. We proposed a way to reduce preoperational anxiety that is simple and matches children's individual characteristics, and this study aimed to assess its effect. The behavioral intervention program using a smartphone application effectively relieved anxiety in children and their parents within 5-10 minutes of the period between the preoperative holding area and entry into the operating room, and it also showed a superior effect compared with premedication.

Cote [13] reported that $0.050-0.075 \mathrm{mg} / \mathrm{kg}$ of midazolam premedication provides happiness to children, while a dose of up to $0.1 \mathrm{mg} / \mathrm{kg}$ can be used for the induction of anesthesia without causing the loss of consciousness. This study used the midazolam premedication dose suggested in the Cote study. We administered the generally used premedication dose in group $\mathrm{M}$, and concomitant use of low-dose premedication with midazolam $0.05 \mathrm{mg} / \mathrm{kg}$ and the behavioral intervention program in group SM. The intervention program using a smartphone application and low-dose midazolam premedication had a superior effect compared with the intervention solely using midazolam premedication. This result can be explained by the features of the mYPAS. The mYPAS used in this study is a tool for an observer to measure the degree of anxiety in children; a total of 27 assessment criteria across 5 sections are measured. This tool measures the degree of anxiety in children under preoperative circumstances and induction of anesthesia, and it has demonstrated high reliability and efficacy [19]. By examining the contents of the assessment criteria, it is seen that lower scores were recorded for children communicating with medical professionals and actively responding to the smartphone application; than children gazing in a still position or being quiet and not playing, the assessment considers anxiety to be further reduced. As this study considered the above criteria, the administration of lowdose midazolam leads to the conversion of children's anxiety into curiosity and pleasure, although the effect of premedication could not induce deep sedation to sufficiently reduce preoperative anxiety. Hence, children were under a light sedated state to actively accept the behavioral intervention program, and it 
resulted in further reduction of preoperative anxiety.

This study considered the factors influencing preoperative anxiety in order to design a behavioral intervention program tailored to the individual characteristics of children. These factors include children's character, the anxiety of parents, immature developmental status, and a history of hospital treatment [1]. The intervention using a smartphone application can easily appeal to various characteristics of children, as various smartphone applications are easily obtainable. It also has the advantage of reducing the anxiety of parents while they observe their child concentrating on the smartphone application. Other possible factors include age data collected from the preoperative visit, psychosocial developmental stage, types of preferred smartphone applications, and familiarity with smartphone applications. The preoperative visit survey was conducted to identify the effect of these factors on the reduction of anxiety in children.

From the survey on psychosocial developmental stage, the gradual stages along with age have been demonstrated as a characteristic of psychosocial development, which is classified in Table 3. When we looked at the preferred smartphone application at each level, there was a strong correlation with the characteristics of psychosocial development. Children aged 12-18 months preferred SoundTouch Interactive ${ }^{\circledR}$, a simple application providing various pictures and sounds of animals, and Pororo Sticker Book ${ }^{\circledR}$, an application that plays the theme song of a famous animated character. Children aged 18-36 months preferred Hutos ${ }^{\circledR}$ vod, an application with a short storytelling animation video, and Pororo Sticker Book ${ }^{\circledR}$, an application with a simple game played using the fingers. Children aged 3648 months preferred Eznetsoft Software ${ }^{\circledR}$, an application with a combination of pictures and storytelling, and Talking Tom Cat ${ }^{\circledR}$, an application that mimics the child's speech and responds to light touch. Children aged 36 months or older mostly preferred Angry Birds ${ }^{\circledR}$, a video game application that stimulates curiosity, enables aim practice, and is complex to control.

Based on the constant trend of correlation between age and psychosocial development shown in Table 1, Fig. 1 shows tendencies in mYPAS values by age according to the intervention (group S and group SM) and according to the point in time. We focus on age to identify the effects of these factors on the reduction of anxiety in children. In group S, the mean mYPAS values were reduced both 5 minutes after the intervention and after entry into the operating room regardless of age, but the mean values in the preoperative holding area were the highest among those aged 1-2 years; the values gradually decreased with older age and plateaued thereafter (Fig. 1A). Also, in group SM, the mean values of mYPAS were reduced both 5 minutes after intervention and after entry into the operating room regardless of age, but the mean values in the preoperative holding area were the highest among those aged 2-3 years; and the values gradually deceased with older age and plateaued thereafter (Fig. 1B). Therefore, early anxiety in the preoperative holding area is largely influenced by age or psychosocial developmental stage. We assume that children aged 4-5 years or younger are vulnerable to anxiety due to their immature psychosocial development. Therefore, more active interventions to counter anxiety are required for younger children.

Lastly, in Fig. 2, we present the survey results regarding the presence of smartphone experience at home to identify the causal relationship between anxiety and familiarity with smartphone applications. At the time the survey was conducted, smartphone marketing was in the early stage, and it was not widespread among children in Korean households; hence, the number of children that had used smartphone applications at home was 9 and 7 in group S and group SM, respectively. The mean mYPAS value was slightly lower in the group that had previously used smartphone applications compared with the group without such experience, but it was not statistically significant. The difference was marginal in group SM. As presented in Table 3, for groups S and SM, the groups with previous experience using smartphone applications showed greater ratios of no-anxiety children; unlike group SM, group S showed a significant difference in the ratio of no-anxiety children between those with and without such experience. The results imply that familiarity with smartphone applications may affect the reduction of anxiety in response to the intervention, and a low dose of midazolam may strongly affect the ratio of no-anxiety children regardless of their familiarity with smartphone applications. However, further statistical tests with a greater amount of data is warranted.

A behavioral intervention program for the reduction of preoperative anxiety can overcome limitations such as complex procedures, high costs, and long hospital stays while providing comparable efficacy to premedication. Recently introduced interventions using portable video games, animation, and video clips are appropriate intervention programs for meeting this purpose [10-13]. This study, however, has additional advantages over the above 3 intervention programs. Smartphone applications are owned by many people, especially parents; hence, the hospital does not need to secure additional devices. In addition, such devices can lead to an effective reduction of anxiety with short training on the day before surgery, even in children without previous exposure to smartphone applications, and are able to provide age-customized games, animation, or video clips all on the same device. In addition, with the widespread use of smartphones, more and more children are using smartphones in Korean households. These circumstances are expected to lead to more effective reduction of anxiety, as training can easily be done at home in advance.

The possibility of failure and the requirement to prepare for this possibility is the limitation of the intervention used in this 
study. We observed 1 case in group $M$ and 2 cases in group $S$ out of 120 cases in which children were administered additional premedication due to the failure of the intervention. The case of failure in group $\mathrm{M}$ involved a child who had presented with highly anxious behavior for dental treatment one year earlier; this child also presented with highly anxious behavior when the intravenous line was secured. The previous hospital treatment experience had a large effect on increasing preoperative anxiety for this child. In such cases, particular consideration should be given to the potential effect of a previous psychological shock from hospital treatment according to the individual's psychosocial developmental status. This anxiety can be overcome by loss of consciousness with an additional administration of premedication; another option, however, is to use the child's preferred smartphone application to overcome the previous psychological shock through curiosity and enjoyment. The two failed cases in group $\mathrm{S}$ included one child whose attention was not drawn by any of the smartphone applications during the survey done a day before the surgery. The other child experienced excessive separation anxiety from family members and thus did not show interest in the smartphone application. The pre-specified factors influencing anxiety and smartphone applications could not predict all of the responses of children, as individual preferences for smartphone applications and individual developmental statuses vary. The above children were able to enter the operat- ing room and focus on the smartphone application under light sedation after an additional intravenous injection of $0.05 \mathrm{mg} / \mathrm{kg}$ midazolam; this can be an effective response. However, the factors that increase anxiety need to be considered beforehand to fundamentally prevent the failure of the intervention. Research is warranted using a greater number of children and a multifaceted approach to assess the statistical significance of factors that may affect preoperative anxiety. In addition, a greater variety of smartphone applications need to be prepared to customize anxiety interventions based on children's complex preferences and fast-changing developmental process.

In conclusion, among Korean children undergoing surgery, an intervention using a smartphone application to improve preoperative anxiety can serve as an effective alternative to premedication, and it can simply and effectively resolve anxiety by being tailored to children's individual characteristics. In addition, the use of low-dose premedication may overcome the limitations of a single intervention; such a strategy presented superior resolution of anxiety in this study. With the current popularity and accessibility of smartphones, we expect the behavioral intervention program using the above methods to have an efficient effect in the future. Therefore, using a behavioral intervention program with a smartphone application is an alternative to premedication, which is a frequently used intervention in current practice.

\section{References}

1. Kain ZN, Mayes LC, O'connor TZ, Cicchetti DV. Preoperative anxiety in children. Predictors and outcomes. Arch Pediatr Adolesc Med 1996; 150: 1238-45.

2. Gwak M. Premedication for your child. Korean J Anesthesiol 2003; 45: 299-303.

3. Kain ZN, Caldwell-Andrews AA, Mayes LC, Weinberg ME, Wang SM, MacLaren JE, et al. Family-centered preparation for surgery improves perioperative outcomes in children: a randomized controlled trial. Anesthesiology 2007; 106: 65-74.

4. Kain ZN, Mayes LC, Caramico LA, Silver D, Spieker M, Nygren MM, et al. Parental presence during induction of anesthesia. A randomized controlled trial. Anesthesiology 1996; 84: 1060-7.

5. Kain ZN, Mayes LC, Wang SM, Caramico LA, Krivutza DM, Hofstadter MB, et al. Parental presence and a sedative premedicant for children undergoing surgery: a hierarchical study. Anesthesiology 2000; 92: 939-46.

6. Kain ZN, Caldwell-Andrews AA, Krivutza DM, Weinberg ME, Gaal D, Wang SM, et al. Interactive music therapy as a treatment for preoperative anxiety in children: a randomized controlled trial. Anesth Analg 2004; 98: 1260-6.

7. Fortier MA, Blount RL, Wang SM, Mayes LC, Kain ZN. Analysing a family-centred preoperative intervention programme: a dismantling approach. Br J Anaesth 2010; 106: 713-8.

8. Golden L, Pagala M, Sukhavasi S, Nagpal D, Ahmad A, Mahanta A. Giving toys to children reduces their anxiety about receiving premedication for surgery. Anesth Analg 2006; 102: 1070-2.

9. Kain ZN, Mayes LC, Wang SM, Caramico LA, Hofstadter MB. Parental presence during induction of anesthesia versus sedative premedication. Anesthesiology 1998; 89: 1147-56.

10. Patel A, Schieble T, Davidson M, Tran MC, Schoenberg C, Delphin E, et al. Distraction with a hand-held video game reduces pediatric preoperative anxiety. Paediatr Anaesth 2006; 16: 1019-27.

11. Lee J, Lee J, Lim H, Son JS, Lee JR, Kim DS, et al. Cartoon distraction alleviates anxiety in children during induction of anesthesia. Anesth Analg 2012; 115: 1168-73.

12. Mifflin KA, Hackmann T, Chorney JM. Streamed video clips to reduce anxiety in children during inhaled induction of anesthesia. Anesth Analg 2012; 115: 1162-7. 
13. Cote CJ. Preoperative preparation and premedication. Br J Anaesth 1999; 83: 16-28.

14. Ahn WS, Kim DG, Bahk JH, Kim HJ. Parental anxiety about the risk of anesthesia of pediatric patients. Korean J Anesthesiol 2004; 47: 34750.

15. Pang LM, Liu MP, Cote CJ. Premedication and induction of anesthesia. A practice of anesthesia for infants and children. 3rd ed. New York, W.B. Saunders Company. 2001, pp 172-95.

16. Kim G, Na HS, Kim SJ, Lim SW, Bae JH. The effect of premedication using a jet-injector in pediatric patients. Korean J Anesthesiol 2007; 53: 291-7.

17. Jeong HJ, Yu JC, Kim KS. Comparison of intranasal and sublingual midazolam as a preanesthestic medication in pediatric patients. Korean J Anesthesiol 1996; 31: 575-80.

18. Kim YJ, Kim CH, Kim YH, Son SC, Choi SJ. The effects of intranasal midazolam on preanesthetic sedation in children. Korean J Anesthesiol 1997; 33: 627-32.

19. Kain ZN, Mayes LC, Cicchetti DV, Bagnall AL, Finley JD, Hofstadter MB. The Yale Preoperative Anxiety Scale: how does it compare with a "gold standard"? Anesth Analg 1997; 85: 783-8. 


\title{
Appendix 1. Modified Yale Preoperative Anxiety Scale
}

\author{
mYPAS Data Sheet
}
A. Activity
B. Vocalizations
C. Emotional Expressivity
D. State of Arousal
E. Use of Parent

\section{A. Activity}

0. Can't code (child not visible)

1. Looking around, curious, playing with toys, reading(or other age appropriate behavior); moves around holding area/ treatment room to get toys or go to parent; may move toward OR equipment

2. Not exploring or playing, may look down, may fidget with hands or suck thumb (blanket); may sit close to parent while waiting, or play has a definite manic quality

3. Moving from toy to parent in unfocused manner, nonactivity derived movements; frenetic/frenzied movement or play; squirming, moving on table, may push mask away or clinging to parent

4. Actively trying to get away, pushes with feet and arms, may move whole body; in waiting room, running around unfocused, not looking at toys or will not separate from parent, desperate clinging

\section{B. Vocalizations}

0 . Can't code (child not visible or can't hear audio)

1. Reading (nonvocalizing appropriate to activity), asking questions, making comments, babbling, laughing, readily answers questions but may be generally quiet; child too young to talk in social situations or too engrossed in play to respond

2. Responding to adults but whispers, "baby talk", only head nodding

3. Quiet, no sounds or responses to adults

4. Whimpering, moaning, groaning, silently crying

5. Crying or may be screaming "no"

6. Crying, screaming loudly, sustained (audible through mask)

\section{Emotional Expressivity}

0 . Can't code (can't see face or child not visible)

1. Manifestly happy, smiling, or concentrating on play

2. Neutral, no visible expression on face

3. Worried (sad) to frightened, sad, worried, or tearful eyes

4. Distressed, crying, extreme upset, may have wide eyes

\section{State of Apparent Arousal}

0. Can't Code (child not visible)

1. Alert, looks around occasionally, notices watches what anesthesiologist does with him/her (could be relaxed)

2. Withdrawn child sitting still and quiet, may be sucking on thumb or face turned into adult

3. Vigilant looking quickly all around, may startle to sounds, eyes wide, body tense

4. Panicked whimpering, may be crying or pushing others away, turns away

\section{E. Use of Parents}

0 . Can't code (child not visible)

1. Busy playing, sitting idle, or engaged in age appropriate behavior and doesn't need parent; may interact with parent if parent initiates the interaction

2. Reaches out to parent(approaches parent and speaks to otherwise silent parent), seeks and accepts comfort, may lean against parent

3. Looks to parents quietly, apparently watches actions, doesn't seek contact or comfort, accepts it if offered or clings to parent

4. Keeps parent at distance or may actively withdraw from parent, may push parent away or desperately clinging to parent and will not let parent go

Total adjusted score $=(\mathrm{A} / 4+\mathrm{B} / 6+\mathrm{C} / 4+\mathrm{D} / 4+\mathrm{E} / 4) \times 100 / 5$ 


\section{Appendix 2. Preoperative Visit Survey Detail}

o Behavior developemental assessment

Can your child say words? or talks

Can your child hold or grasp an object?

Can your child finger feed?

Can your child indicate wants?

What do you and your child enjoy doing together?

What are his/her favorite play activities?

Does he/she become upset in the presence of unfamiliar people?

Does he/she become upset when parents leave for a short time?

What kind of activities does he /she when he/she become upset?

Have there been any stressful events in the family lately?

o Who is his or her favorite family member? (Mother/Father/Grandmother/Grandfather)

o Who is going to preoperative holding area with him/her?

(Mother/Father/Grandmother/Grandfather)

o Have you and your child enjoyed playing smartphone application together? (Y/N)

When did the smartphone application playing begin?

How long does the smartphone application playing time in a day?

o What are his/her favorite smartphone application?

1. SoundTouch interactive (@Soundtouch interactive ${ }^{\circledR}$, Israel)

2. Pororo Sticker Book ${ }^{\circledR}$ ( $\subset$ OCON Animation Studio, South Korea)

3. Hutos ${ }^{\circledR}$ VOD (c) Cotton Interactive, South Korea)

4. Talking Tom cat ${ }^{\circledR}$ (@Out Fit 7, Slovenia)

Talking Rex the dinosaur ${ }^{\circledR}$ (৫) Out Fit 7, Slovenia)

Talking Baby hippo ${ }^{\circledR}$ (С) Out Fit 7, Slovenia)

Talking Larry the bird ${ }^{\circledR}$ (৫) Out Fit 7, Slovenia)

5. Eznetsoft software ${ }^{\circledR}$ “The little Mermaid”, "Hansel and Gretel” (৫Eznetsoft, South Korea)

6. Angry birds ${ }^{\circledR}$ (@Rovio Entertainment LTD., Finland) 